\title{
Effect of variation of the average daily volume and traffic growth rate on flexible pavements performance
}

\author{
Efecto de la variación del volumen diario medio y de la tasa de crecimiento del \\ tráfico en el desempeño de los pavimentos flexibles
}

\author{
Amanda Sati Hirooka Koshigoe ${ }^{1}$ Fernando César Vargas Zanoni ${ }^{1}$ Carlos Alberto Prado Silva Júnior ${ }^{1}$ \\ Heliana Barbosa Fontenele ${ }^{1 *}$
}

Recibido 15 de febrero de 2017, aceptado 19 de febrero de 2018

Received: February 15, 2017 Accepted: February 19, 2018

\begin{abstract}
Pavement design, initially based on empirical methods, has been improved and, currently, there is a tendency to replace these methods by mechanistic-empirical ones. This new methodology uses detailed information on traffic, climate and pavement structure to obtain accurate performance predictions, providing a better design. In this study, it was performed a sensitivity analysis of flexible pavements to investigate the effect that the variation of annual average daily traffic (AADT) and traffic growth rate has on structural pavement responses. Therefore, simulations were done using two computer programs, MEPDG and AASHTOWare Pavement ME Design, whose results indicated that the pavement has sensitivity to both variations that were studied (AADT and traffic growth rate), demonstrating higher deterioration values when the traffic growth rate was nonlinear. It was also concluded that the difference between sensitivity values obtained by both programs was insignificant.
\end{abstract}

Keywords: Mechanistic-empirical software, MEPDG, AASHTOWare Pavement ME Design.

\section{RESUMEN}

El diseño del pavimento, inicialmente basado en métodos empíricos, ha sido mejorado y, actualmente hay una tendencia a sustituir estos métodos por métodos empírico-mecánicos. Esta nueva metodología utiliza la información detallada del tráfico, del clima y de la estructura del pavimento para obtener predicciones precisas de desempeño, proporcionando un mejor diseño. En este trabajo, se realizó un análisis de sensibilidad de los pavimentos flexibles para investigar el efecto que tiene la variación del tránsito promedio diario anual (TPDA) y la tasa de crecimiento del tráfico en las respuestas estructurales al pavimento. Por lo tanto, las simulaciones se realizaron mediante dos programas de ordenador, el programa MEPDG y el AASHTOWare Pavement ME Design, cuyos resultados indicaron que el pavimento tiene sensibilidad a ambas variaciones estudiadas (TPDA y tasa de crecimiento del tráfico), demostrando mayores valores de deterioro cuando la tasa de crecimiento del tráfico fue no lineal. También se concluyó que la diferencia entre los valores de sensibilidad obtenidos por los dos programas era insignificante.

Palabras clave: Mechanistic-empirical software, MEPDG, AASHTOWare Pavement ME Design.

1 Civil Construction Department. Universidade Estadual de Londrina. Londrina-PR, Brasil. E-mail: amandakoshigoe@ gmail. com; fercvz@gmail.com; cprado@uel.br; heliana@uel.br

Corresponding Author 


\section{INTRODUCTION}

Several factors may contribute to the pavement degradation, such as environmental and climatic agents, quality of used materials and design parameters. It is therefore of great importance to study the traffic volume, which indicates the number of vehicles passing the road; as well as their growth rate to understand how the variation of these parameters affects the quality of the pavement structure. Also, depending on these parameters, it is necessary to analyze the sensitivity of the pavement using computer programs to optimize pavement design.

The pavement design is defined as a process to determine the thicknesses of the constituent layers (surface, subbase and subgrade) so that these resist, transmit and distribute the load imposed by traffic, avoiding excessive deformation, including the pavement rupture. Therefore, the design should ensure adequate performance during operating life.

In recent years, the design of pavement has been based on empirical methods, which were developed in the 60 s. Such methods were defined as those based solely on experimental data or experience. It is noteworthy that over time, however, the characteristics of the types of vehicles and transported loads changed, limiting the use of this method [1].

The analysis of the pavement by the mechanisticempirical method, on the other hand, is made with the aid of computer programs. The process of analysis starts from a pre-dimensioned structure in which different values of design parameters are inserted, such as tire pressure; traffic volume; materials used on the pavement; thickness of the layers; weather data; among others. From these data, the program determines the structural responses and calculates the damages on the pavement, which are then compared to the performance criteria set by the regulation. If these criteria are not met, it is necessary to vary the design parameters until the ideal condition is achieved [4-5].

In this study, the MEPDG and AASHTOWare Pavement ME Design software were used. In a simplified manner, MEPDG can be described as a program which analyzes the input data inserted therein, such as traffic characteristics, weather and materials used in the structure; applying numerical models to estimate accumulated damage during the pavement life [6-7]. In 2008, MEPDG underwent a transition to the AASHTOWare program package, coming to be called Darwin ME. In 2013, this software became commercially available under a new name: AASHTOWare Pavement ME Design [9].

Studies of pavement sensitivity related to the variation of the design parameters, using the mechanisticempirical method, indicate that the variation of the traffic volume parameters has a greater influence on bottom-up fatigue cracking. As for the traffic growth rate, some authors state that the variation on the traffic growth factors has low interference in roughness, permanent deformation and fatigue cracking issues [8].

\section{MATERIAL AND METHODS}

For this study, it was defined the design parameters to be varied, in order to determine the influence of these variations on the performance of flexible pavements. Therefore, it was decided to change the following parameters: annual average daily traffic (AADT) and traffic growth rate.

With the results of the performance curves obtained by the pavement analysis program, which were generated from the input data that considered the variation of the design parameters, graphical representations were made relating the variations of design parameters with various pavements deformities accumulated over the 20 years project period, such as longitudinal cracking, fatigue cracking, permanent deformation and roughness index.

\section{Traffic}

A study conducted by the Regulatory Agency of Transportation of São Paulo State determined, from counts made in the SP 160 highway in 2009, that the AADT was 10,993 vehicles/day. Thus, for the analyzes of this research, the study above was taken as basis, considering five AADT values: 8,993 vehicles/day; 9,993 vehicles/day; 10,993 vehicles/day; 11,993 vehicles/day and 12,993 vehicles/day. While the AADT values were varied, the other parameters were kept fixed (linear traffic growth of $4 \%$ ).

Furthermore, the variation of traffic growth rate was made adopting the following values: $4 \%, 6 \%, 8 \%, 10 \%$ and $12 \%$. These values were used since, in Brazil, the traffic growth factor to be used as a reference for pavement 
design is $3 \%$ [2]. It was also examined two types of growth rate, linear and nonlinear. In this case, the value of the AADT was kept fixed at 10,993 vehicles/day.

In Brazil, it is still widely used the design method that deliberates a tire pressure of $552 \mathrm{kPa}(80 \mathrm{psi})$. A situation that is far from reality, which presents much higher values. Studies indicate that the average tire pressure in Brazil is $827 \mathrm{kPa}$ (120psi) [3], therefore, all analyzes were made considering two pressures: 552 $\mathrm{kPa}(80 \mathrm{psi})$ and $827 \mathrm{kPa}$ (120 psi).

\section{Structure}

It was considered a hypothetical pavement structure with three layers settled above the subgrade (Table $1)$.

Table 1. Characteristics of the hypothetical pavement structure.

\begin{tabular}{|c|c|c|c|}
\hline Layer & $\begin{array}{c}\text { Thickness } \\
(\mathbf{c m})\end{array}$ & $\begin{array}{c}\text { Poisson } \\
\text { Coefic. }\end{array}$ & $\begin{array}{c}\text { Modulus } \\
\text { of elasticity } \\
\text { (Mpa) }\end{array}$ \\
\hline 1 (surface) & 12.5 & 0.3 & - \\
\hline 2 (base) & 20 & 0.4 & 400 \\
\hline 3 (subbase) & 25 & 0.4 & 200 \\
\hline 4 (subgrade) & $\infty$ & 0.45 & 70 \\
\hline
\end{tabular}

\section{Climate}

The weather condition of Orlando (Florida - USA) was adopted due to the rainfall similarity to the Immigrants highway region, considering a depth of $10 \mathrm{~m}$ to the water table.

\section{RESULTS AND DISCUSSION}

The graphs of deteriorations according to the variation of the AADT, the linear traffic growth rate and the nonlinear traffic growth rate are shown in Figures 1, 2 and 3, respectively. From the data of each graph is possible to check the sensitivity values related to each variation of the design parameter.
In Figure 1, the results of the longitudinal cracking (surface-down) provided by MEPDG related to the adoption of the tire pressure of $552 \mathrm{kPa}(80 \mathrm{psi})$, there is a variation of $22.65 \%$ in the deterioration of the pavement when the AADT increased from 8,993 vehicles/day to 12,993 vehicles/day. When the analysis was performed with AASHTOWare Pavement ME Design, the change was of $22.98 \%$. Regarding the application of $827 \mathrm{kPa}$ (120 psi) pressure, the longitudinal cracking shows the same behavior, again with higher values in the analyzes with MEPDG, presenting a variation of $21.44 \%$. The results obtained with AASHTOWare Pavement ME Design, in turn, showed a variation of $23.26 \%$.

When evaluating the results obtained by MEPDG for the various pressures, in the case of longitudinal cracking (surface-down), it was observed that the deterioration from the pressure of $827 \mathrm{kPa}(120 \mathrm{psi})$ exceeded by more than $10 \%$ the deterioration resulting from the pressure of $552 \mathrm{kPa}(80 \mathrm{psi})$. However, the AASHTOWare Pavement ME Design displayed an opposite behavior, the values obtained for pressures of $827 \mathrm{kPa}$ (120 psi) were lower than the pressures of 552 $\mathrm{kPa}(80 \mathrm{psi})$, resulting in a reduction of more than $2 \%$.

The fatigue cracking (bottom-up), considering the pressure of $552 \mathrm{kPa}(80 \mathrm{psi})$, presents a variation of $20.20 \%$ when analyzed by MEPDG. When the tire pressure was elevated to $827 \mathrm{kPa}$ (120 psi), the variation increased to $20.13 \%$. With AASHTOWare Pavement ME Design, the variation was $19.89 \%$ for the pressure of $552 \mathrm{kPa}(80 \mathrm{psi})$, while for pressure of $827 \mathrm{kPa}(120 \mathrm{psi})$ was $20.43 \%$.

For the results obtained considering different pressures, in the case of fatigue cracking (bottomup), it was observed that the deterioration from the $827 \mathrm{kPa}$ (120 psi) pressure exceeded by more than $15 \%$ the deterioration resulting from the pressure of $552 \mathrm{kPa}$ (80 psi) when analyzed by MEPDG. When using AASHTO Ware Pavement ME Design, in turn, the increase was of approximately $12 \%$. 

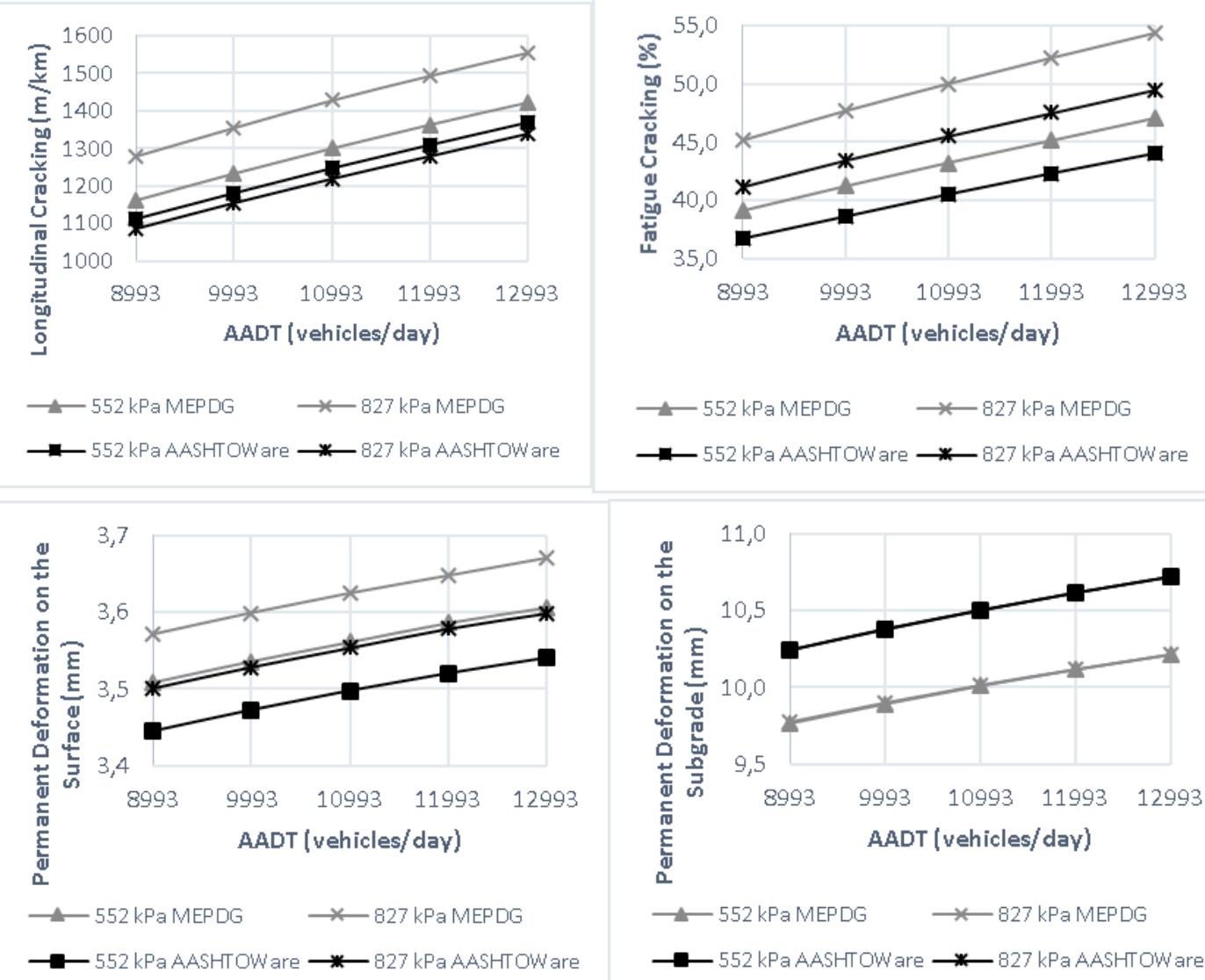

$\longrightarrow 552 \mathrm{kPaMEPDG} \quad \longrightarrow-627 \mathrm{kPaMEPDG}$

$\rightarrow-552 \mathrm{kPaAASHTOW}$ are $\rightarrow$ * $827 \mathrm{kPaAASHTOW}$ are
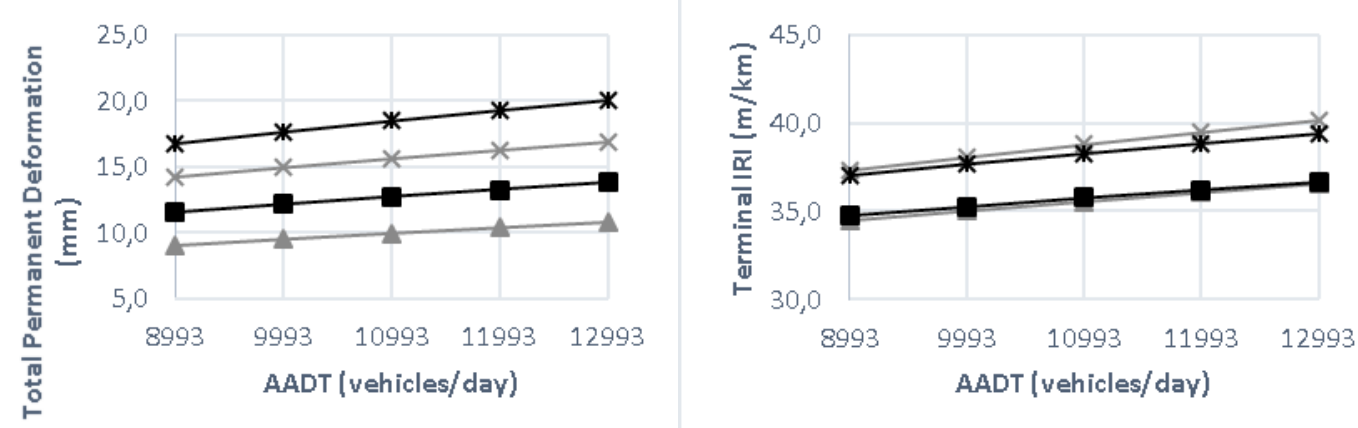

$-552 \mathrm{kPaMEPDG} \quad \longrightarrow 827 \mathrm{kPaMEPDG}$

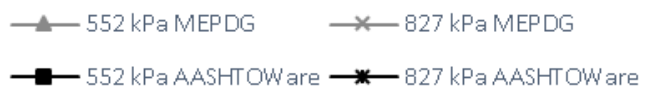

Figure 1. Deteriorations values caused in the pavement related to the variation of the annual average daily traffic (AADT). 
Evaluating permanent deformation on the surface course with MEPDG to the pressure of $552 \mathrm{kPa}$ ( 80 psi), there is little variation between the minimum and maximum values, reaching only $2.82 \%$. Even increasing the pressure to $827 \mathrm{kPa}(120 \mathrm{psi})$, there was little effect, since the values fluctuated from 3.6 $\mathrm{mm}$ to $3.7 \mathrm{~mm}$. Thus, the increase in deterioration had not reached $2 \%$ when the tire pressure was increased from $552 \mathrm{kPa}$ (80 psi) to $827 \mathrm{kPa}(120 \mathrm{psi})$.

The permanent deformation on the subgrade, in turn, showed higher sensitivity than on the surface. Considering the pressure of $552 \mathrm{kPa}(80 \mathrm{psi})$ with analysis by MEPDG, there was a variation of $4.57 \%$. When the pressure was changed to $827 \mathrm{kPa}(120 \mathrm{psi})$ there was an identical behavior at the pressure of $552 \mathrm{kPa}(80 \mathrm{psi})$, with no difference between the obtained values. When the analysis was performed with AASHTOWare Pavement ME Design, the program obtained slightly higher deterioration values, but the same behavior was observed, reaching a variation between the predicted values of $4.66 \%$.

It is expected that the total permanent deformation is superior to the deformation on the surface and subgrade. In this case, the variation of the values of deterioration provided by both programs was almost the same, being $19.25 \%$ to the pressure of $552 \mathrm{kPa}$ (80 psi) and $19.27 \%$ for the pressure of $827 \mathrm{kPa}(120$ psi). For this situation, it was possible to verify that the deformation values obtained by MEPDG were higher than AASHTOWare Pavement ME Design only for the permanent deformation on the surface.

Moreover, it became clear that the pressure of $827 \mathrm{kPa}$ (120 psi), compared to the deterioration caused by the $552 \mathrm{kPa}$ tire pressure (80 psi), always induces higher deterioration in the pavements, except the permanent deformation on the subgrade, which was not influenced by the pressure variation. It was also observed an increase of almost $60 \%$ in total permanent deformation when analyzed by MEPDG and approximately $45 \%$ for analysis with AASHTOWare Pavement ME Design.

The International Roughness Index (IRI) calculated by MEPDG showed a variation of $6.08 \%$ between the maximum and minimum values for the pressure of $552 \mathrm{kPa}(80 \mathrm{psi})$. With the growth of the pressure to $827 \mathrm{kPa}(120 \mathrm{psi})$, a variation of $7.63 \%$ was observed. Thus, it was noticed an increase of almost $10 \%$ as the pressure was raised from $552 \mathrm{kPa}(80 \mathrm{psi})$ to $827 \mathrm{kPa}$ (120 psi). However, when the analysis was done using AASHTOWare Pavement ME Design, variations were lower, being $5.36 \%$ to the pressure of $552 \mathrm{kPa}(80 \mathrm{psi})$ and $6.23 \%$ for the pressure of $827 \mathrm{kPa}(120 \mathrm{psi})$.

In Figure 2, the results of the longitudinal cracking (surface-down) provided by MEPDG related to the adoption of $552 \mathrm{kPa}$ tire pressure ( $80 \mathrm{psi}$ ), a variation of $24.92 \%$ was observed in the deterioration of the pavement when the growth rate increased from $4 \%$ to $12 \%$. When the analysis was performed with AASHTOWare Pavement ME Design, the change was of $25.41 \%$. Concerning the application of $827 \mathrm{kPa}(120$ psi) pressure, the longitudinal cracking shows the same behavior, again with higher values in the analyzes with MEPDG, displaying a variation of $22.71 \%$. The results obtained with AASHTOWare Pavement ME Design showed a variation of $25.73 \%$.

When analyzing the results obtained by MEPDG for the various pressures in the case of longitudinal cracking (surface-down), it was observed that the deterioration from the $827 \mathrm{kPa}$ (120 psi) pressure exceeded by more than $7 \%$ the deterioration resulting from the pressure of $552 \mathrm{kPa}(80 \mathrm{psi})$. However, the AASHTOWare Pavement ME Design provided an opposite behavior, the values obtained for pressures of $827 \mathrm{kPa}(120 \mathrm{psi})$ were lower than the pressures of $552 \mathrm{kPa}(80 \mathrm{psi})$, resulting in a reduction of more than $2 \%$.

The fatigue cracking (bottom-up), considering the pressure of $552 \mathrm{kPa}(80 \mathrm{psi})$, presents a variation of $24.30 \%$ when analyzed by MEPDG. When the tire pressure was elevated to $827 \mathrm{kPa}(120 \mathrm{psi})$, the variation increased to $23.43 \%$. With AASHTOWare Pavement ME Design, variation was $24.19 \%$ for the pressure of $552 \mathrm{kPa}$ (80 psi), while for the pressure of $827 \mathrm{kPa}$ (120 psi) was $23.95 \%$.

When assessing the results obtained for the various pressures, in the case of fatigue cracking (bottom-up), it was observed that the deterioration from the $827 \mathrm{kPa}$ pressure (120 psi) exceeded by more than $15 \%$ the deterioration resulting from $552 \mathrm{kPa}$ pressure $(80 \mathrm{psi})$ when analyzed by MEPDG. Using AASHTOWare Pavement ME Design, in turn, the increase was of approximately $12 \%$. 


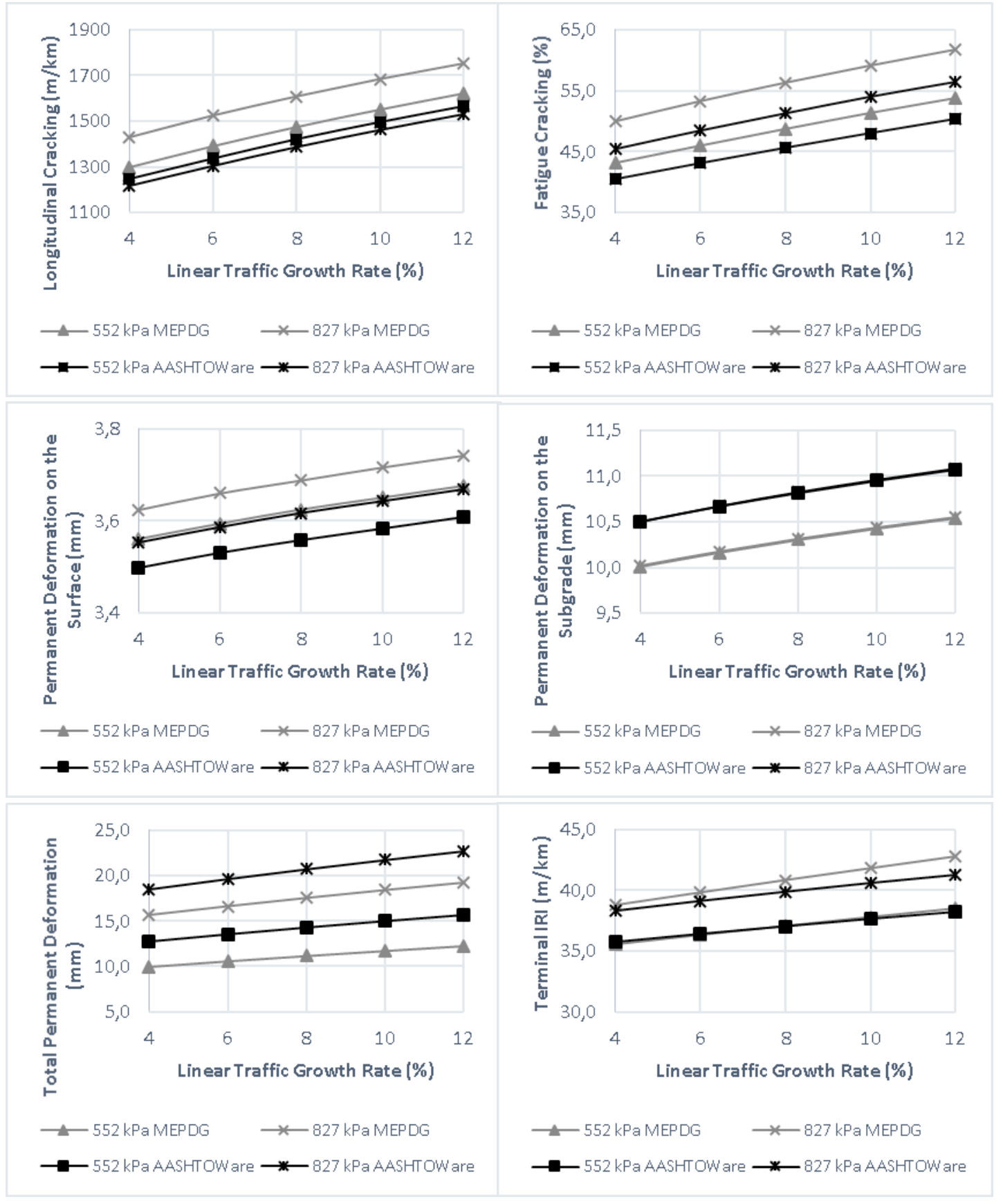

Figure 2. Deteriorations values caused in the pavement related to the variation of the linear traffic growth rate. 
Evaluating permanent deformation on the surface course with MEPDG to the pressure of $552 \mathrm{kPa}$ ( 80 $\mathrm{psi}$ ), there is little variation between the minimum and maximum values, reaching only $3.22 \%$. Even increasing the pressure to $827 \mathrm{kPa}(120 \mathrm{psi})$, there was little effect, since the values ranged from 3.6 $\mathrm{mm}$ to $3.7 \mathrm{~mm}$. When the analyzes were made with AASHTOWare Pavement ME Design, variations values were similar to those obtained with MEPDG.

The permanent deformation on the subgrade, in turn, showed higher sensitivity than on the surface. Considering the pressure of $552 \mathrm{kPa}(80 \mathrm{psi})$ with analysis by MEPDG, there was a variation of $5.33 \%$. When the pressure was changed to $827 \mathrm{kPa}(120 \mathrm{psi})$ there was an identical behavior as at the pressure of $552 \mathrm{kPa}$ (80 psi), with no difference between the obtained values. When the analysis was performed with AASHTOWare Pavement ME Design, the program obtained slightly higher deterioration values, but the same behavior was observed, reaching a variation between the predicted values of $5.44 \%$.

In the case of total permanent deformation, the variation between the values of the deterioration obtained by both programs continued to be similar, being $23.01 \%$ for the pressure of $552 \mathrm{kPa}(80 \mathrm{psi})$ with analysis by MEPDG and $23.10 \%$ for the pressure of $827 \mathrm{kPa}$ (120 psi). When using AASHTOWare Pavement ME Design, the variations changes were $23.04 \%$ for the pressure of $552 \mathrm{kPa}(80 \mathrm{psi})$ and $22.95 \%$ for the pressure of $827 \mathrm{kPa}(120 \mathrm{psi})$. It is important to observe that the increase in tire pressure caused a large growth in this type of deterioration, exceeding by almost $60 \%$ when analyzed by MEPDG, and getting around $45 \%$ when analyzed by AASHTOWare Pavement ME Design.

Moreover, it became clear that the pressure of 827 $\mathrm{kPa}$ (120 psi), compared to the deterioration caused by the $552 \mathrm{kPa}$ tire pressure ( $80 \mathrm{psi}$ ), always provokes higher deterioration in the pavements, except the permanent deformation on the subgrade, which was not influenced by the tire pressure variation.

The International Roughness Index (IRI) calculated by MEPDG, showed a variation of $8.29 \%$ between the maximum and minimum values for the pressure of $552 \mathrm{kPa}(80 \mathrm{psi})$. With the growth of the pressure to $827 \mathrm{kPa}(120 \mathrm{psi})$, a variation of $10.32 \%$ was observed. Thus, it was noticed an increase of almost
$12 \%$ as the pressure was raised from $552 \mathrm{kPa}(80 \mathrm{psi})$ to $827 \mathrm{kPa}$ (120 psi). However, when the analysis was done using AASHTOWare Pavement ME Design, variations were lower, being $6.77 \%$ for the pressure of $552 \mathrm{kPa}(80 \mathrm{psi})$ and $7.79 \%$ for the pressure of $827 \mathrm{kPa}(120 \mathrm{psi})$.

In Figure 3, the results of the longitudinal cracking (surface-down) provided by MEPDG related to the adoption of $552 \mathrm{kPa}$ tire pressure ( $80 \mathrm{psi}$ ), a variation of $46.89 \%$ was observed in the pavement deformation values when the growth rate increased from $4 \%$ to $12 \%$. When the analysis was performed with the AASHTOWare Pavement ME Design, the change was $49.05 \%$. In relation to the application of $827 \mathrm{kPa}(120$ psi) pressure, the longitudinal cracking shows the same behavior, again with higher values in the analyzes with MEPDG indicating a variation of $40.75 \%$. The results obtained with AASHTOWare Pavement ME Design showed a variation of $50.43 \%$.

When analyzing the results obtained by MEPDG for the various pressures, in the case of longitudinal cracking (surface-down), it was observed that the deterioration from the $827 \mathrm{kPa}$ (120 psi) pressure exceeded by more than $5 \%$ the deterioration resulting from pressures of $552 \mathrm{kPa}$ (80 psi). However, the AASHTOWare Pavement ME Design displayed an opposite behavior, the values obtained for pressures of $827 \mathrm{kPa}(120 \mathrm{psi})$ were lower than the pressures of $552 \mathrm{kPa}(80 \mathrm{psi})$, resulting in a reduction of more than $1 \%$.

The fatigue cracking (bottom-up), considering the pressure of $552 \mathrm{kPa}(80 \mathrm{psi})$, presents a variation of $52.22 \%$ when analyzed by MEPDG. When the tire pressure was increased to $827 \mathrm{kPa}$ (120 psi), the variation increased to $47.39 \%$. With AASHTOWare Pavement ME Design, variation was $53.56 \%$ for the pressure of $552 \mathrm{kPa}(80 \mathrm{psi})$, while for the pressure of $827 \mathrm{kPa}(120 \mathrm{psi})$ was $50.63 \%$.

When analyzing the results obtained for the different pressures, in the case of fatigue cracking (bottomup), it was observed that the deterioration from the pressures of $827 \mathrm{kPa}(120 \mathrm{psi})$ exceeded by more than $12 \%$ the deterioration resulting from $552 \mathrm{kPa}$ (80 psi) pressure when analyzed by MEPDG. Using AASHTOWare Pavement ME Design, in turn, the increase was over $10 \%$. 
It is noteworthy that the pressure of $827 \mathrm{kPa}(120 \mathrm{psi})$, compared to the deterioration caused by the $552 \mathrm{kPa}$ tire pressure $(80 \mathrm{psi})$, causes higher deterioration in the pavements, except the longitudinal cracking when analyzed by AASHTOWare Pavement ME Design. Assessing the permanent deformation on the surface with MEPDG for the pressure of $552 \mathrm{kPa}(80 \mathrm{psi})$, there is relatively little variation between the minimum and maximum values, reaching $6.52 \%$. By increasing the pressure to $827 \mathrm{kPa}(120 \mathrm{psi})$, there was little effect, since the values ranged from $3.6 \mathrm{~mm}$ to $3.9 \mathrm{~mm}$. When the analyzes were made with AASHTOW are Pavement ME Design, variations values were very close to those obtained with MEPDG.

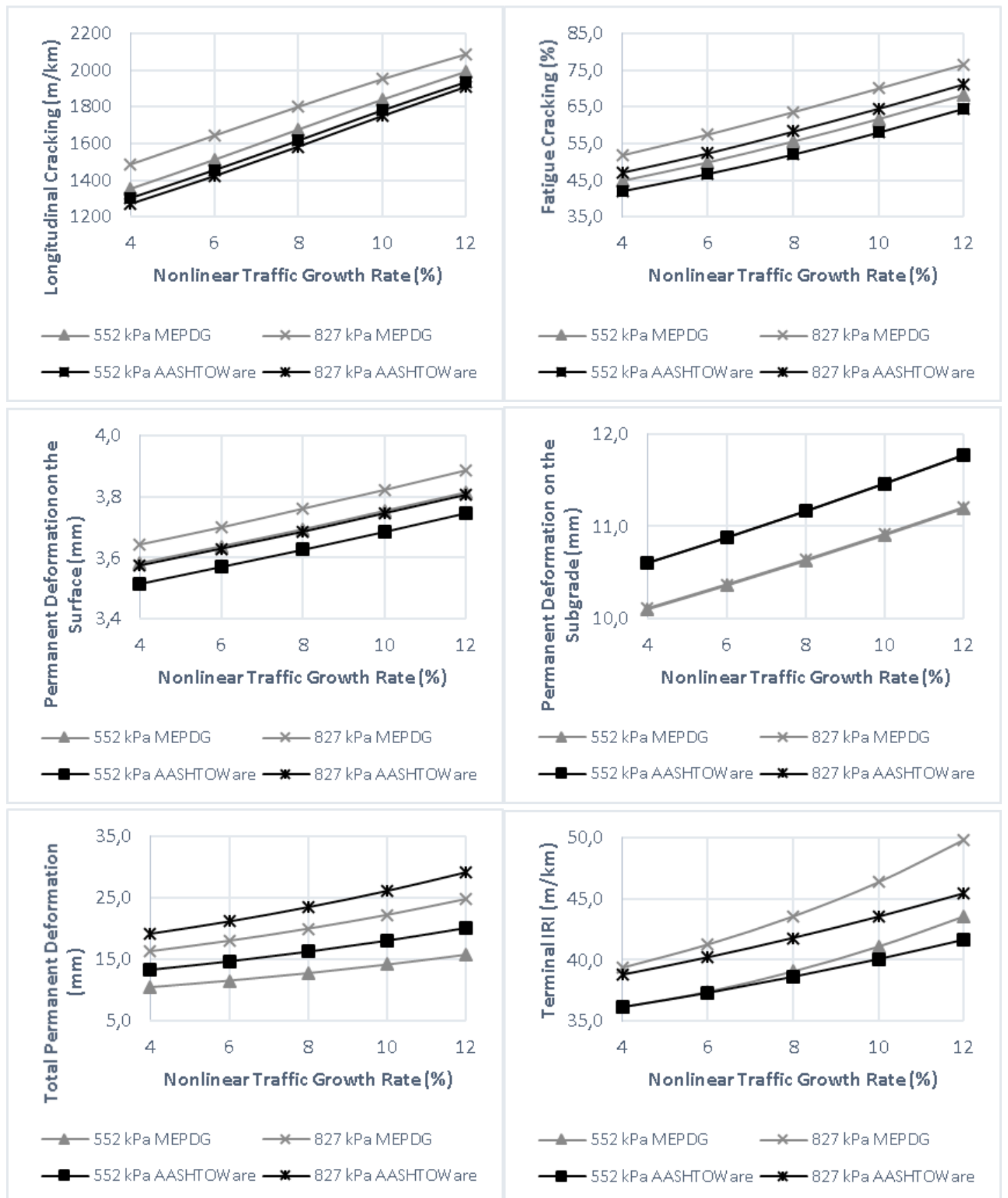

Figure 3. Deteriorations values caused in the pavement related to the variation of the nonlinear traffic growth rate. 
is relatively little variation between the minimum and maximum values, reaching $6.52 \%$. By increasing the pressure to $827 \mathrm{kPa}$ (120 psi), there was little effect, since the values ranged from $3.6 \mathrm{~mm}$ to $3.9 \mathrm{~mm}$. When the analyzes were made with AASHTOWare Pavement ME Design, variations values were very close to those obtained with MEPDG.

The permanent deformation on the subgrade, in turn, showed higher sensitivity than on the surface. Considering the pressure of $552 \mathrm{kPa}(80 \mathrm{psi})$ with analysis by MEPDG, there was a variation of $10.86 \%$. When the tire pressure was changed to $827 \mathrm{kPa}$ (120 psi) there was an identical behavior as at the pressure of $552 \mathrm{kPa}(80 \mathrm{psi})$, with no difference between the obtained values. When the analysis was performed with the AASHTOWare Pavement ME Design, the program obtained slightly higher deformation values, but the same behavior was observed, reaching a variation between the predicted values of $11.03 \%$.

In the case of total permanent deformation, the variation values obtained by both programs continued to be similar, being $52.48 \%$ for the pressure of $552 \mathrm{kPa}(80 \mathrm{psi})$ with analysis by MEPDG and $52.65 \%$ for the pressure of 827 $\mathrm{kPa}$ (120 psi). When using AASHTOWare Pavement ME Design, the variation changes were $52.39 \%$ for the pressure of $552 \mathrm{kPa}(80 \mathrm{psi})$ and $52.05 \%$ for the pressure of $827 \mathrm{kPa}(120 \mathrm{psi})$. It is noteworthy that the increase in tire pressure caused a large elevation in this type of deterioration, exceeding by almost $60 \%$ when analyzed by MEPDG, and getting around $45 \%$ when analyzed by AASHTOWare Pavement ME Design.

The International Roughness Index (IRI) showed a variation of $20.71 \%$ between the maximum and minimum values when analyzed by MEPDG to a pressure of $552 \mathrm{kPa}(80 \mathrm{psi})$. With the growth of the pressure to $827 \mathrm{kPa}(120 \mathrm{psi})$, a variation of $26.37 \%$ was observed. Thus, it was noticed a rise of almost $15 \%$ as the pressure of $552 \mathrm{kPa}(80 \mathrm{psi})$ increased to $827 \mathrm{kPa}$ (120 psi). However, when the analysis was done using AASHTOWare Pavement ME Design, variations were lower, being $15.10 \%$ to the pressure of $552 \mathrm{kPa}$ ( 80 psi) and $17.11 \%$ for the pressure of $827 \mathrm{kPa}(120 \mathrm{psi})$.

The graphs of Figure 4, in turn, represent variations of deterioration according to the change of the traffic growth behavior. When comparing the results related to different growth rates; it was observed that the deterioration values obtained for the growth rate of nonlinear behavior were always higher than the deterioration values of the linear growth rate. Such behavior was observed both in the results obtained by MEPDG, as in the results obtained by AASHTOWare Pavement ME Design. Furthermore, it was noticed a significant variation between the minimum and maximum values, revealing a higher sensitivity of the pavement to the traffic growth of nonlinear behavior, as represented in the graphs of Figure 4.

It is verified that the sensitivity of deteriorations almost doubled in all cases when the traffic growth rate was nonlinear. This occurrence may be explained by the fact that the nonlinear growth is based on an exponential function, which represents superior variation than the linear function.

\section{CONCLUSIONS}

Comparing both software versions, in general, there were minor differences in the sensitivity values obtained by MEPDG and AASHTOWare Pavement ME Design. Nevertheless, these differences may be due to some disparity in the program settings, since there were changes from MEPDG to AASHTOWare Pavement ME Design. It is noteworthy that AASHTOWare Pavement ME Design is still in development and undergoes periodic changes, so it is possible that the model for some predictions is still being improved.

Analyzing the results found herein, it can be concluded that the AADT variation has an influence on the pavement performance. Among all evaluated deteriorations, the longitudinal cracking and fatigue cracking were those which presented greater sensitivity. Hence, it is recommended conducting an appropriate traffic survey with a historical basis to achieve a reliable AADT value that must be compatible with a realistic situation. An adequate AADT value would lead to an accurate deterioration prediction and, thus, enable the development of a pavement design with good performance.

The variation of the linear growth rates also influenced the pavement performance, presenting a similar behavior to the variation of AADT, but with slightly higher sensitivity. The highest sensitivity, however, occurred when there was a variation in the growth 


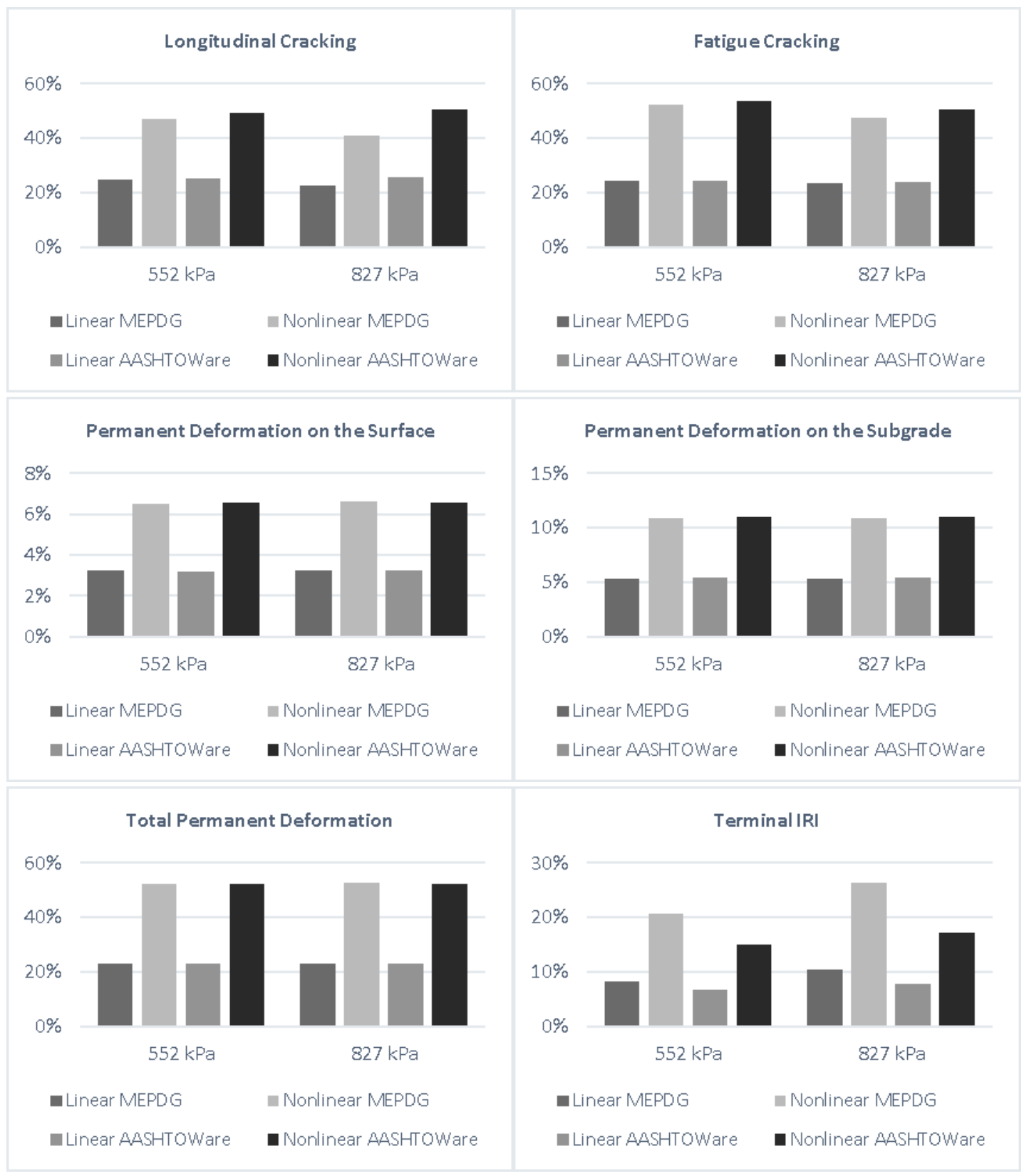

Figure 4. Deteriorations sensitivity related to the linear and nonlinear growth rates.

rates of nonlinear behavior. In this case, it was obtained values that exceeded approximately in 50\% the values of variation regarding the linear growth rate. Based on this, it is assured the importance of considering the nonlinear growth behavior in traffic study, since the use of linear growth rate would result in improper pavement design. Therefore, it is necessary to perform appropriate traffic surveys as well as statistical studies with a historical basis to obtain the correct growth rate.

In Brazil, $827 \mathrm{kPa}(120 \mathrm{psi})$ tire pressure portrays the reality of today's cargo vehicles, thus it is important to update the pavement design process. It is still 
widely used that method that considers a standard axis of $8.2 \mathrm{tf}$ with a tire pressure of $552 \mathrm{kPa}$ ( $80 \mathrm{psi})$, which is far from the real situation, causing improper pavement dimensioning and, that way, reducing its operating life.

\section{ACKNOWLEDGEMENT}

The authors would like to thank Fundação Araucária/ PR (Edital 14/2011) and CNPq (Conselho Nacional de Desenvolvimento Científico e Tecnológico, Brasil) for their financial aid to this research.

\section{REFERENCES}

[1] R.L. Carvalho and C.W. Schwartz. Comparisons of flexible pavement designs: AASHTO empirical vs. NCHRP 1-37A mechanisticempirical. Transportation Research Record: Journal of the Transportation Research Board. TRB 2006 Annual Meeting CD-ROM. Washington, D. C., 2006.

[2] DNIT - Departamento Nacional de Infraestutura de Transporte. Diretoria de Planejamento e Pesquisa. Coordenação Geral de Estudos de Pesquisa. Manual de Estudos de Tráfego. Rio de Janeiro, 2006.

[3] J.L. Fernandes Junior, J.C. Paes and P.A. Pereira. A. Avaliação dos efeitos das solicitações de tráfego sobre o desempenho de pavimentos flexíveis portugueses e brasileiros. Revista Pavimentação, Ano II, $\mathrm{N}^{\circ}$ 5, pp. 28-38. Associação Brasileira de Pavimentação - ABPv. Rio de Janeiro, 2007.
[4] H. B. Fontenele. Representação do tráfego de veículos rodoviários de carga através de espectros de carga por eixo e seu efeito no desempenho dos pavimentos. 2011. 287 p. Tese (Doutorado). Escola de Engenharia de São Carlos, Universidade de São Paulo. São Carlos, 2011.

[5] H.B. Fontenele and J.L. Fernandes Junior. $\mathrm{O}$ efeito da caracterização do tráfego no desempenho do pavimento flexível. Ciência \& Engenharia. Vol. 23, pp. 9. 2014.

[6] S. Kim, H. Ceylan, D. Ma and K. Gopalakrishnan. Calibration of pavement ME Design and mechanistic-empirical pavement design guide performance prediction models for Iowa pavement systems. ASCE Journal of Transportation Engineering. Vol. 21, Issue 10. 2014.

[7] NCHRP - National Cooperative Highway Research Program. Guide for MechanisticEmpirical Design of New and Rehabilitated Pavement Structures. Final Report NCHRP 1-37 A. Champaign, Illinois. 2004.

[8] S. Shahji. Sensitivity analysis of AASHTO'S 2002 flexible and rigid pavement design methods. 2006. Thesis (Master of Science). College of Engineering and Computer Sciencel of the University of Central Florida at Orlando, 2006.

[9] D.H. Timm, M.M. Robbins, N. Tran and C. Rodezno. Flexible Pavement Design - State of the Practice. National Center for Asphalt Technology (NCAT) at Auburn University, 2014. 